\title{
Integrating self-regulated learning and discovery learning into English lesson plan
}

\author{
Ni Kadek Heny Sayukti \\ English Language Education, School of Post-Graduate Studies, Universitas Pendidikan Indonesia
}

\begin{abstract}
The notion of learner-centeredness has been embedded in the National Curriculum of Indonesia, 2013 Curriculum. However, most of the teachers seem to be hardly acquainted with the concept of Self-Regulated Learning (SRL) and discovery learning in the lesson planning. Considering the phenomenon, this study intends to explore the concept of SelfRegulated Learning in the lesson plan of English subject for a tenth-grade level by employing a qualitative design with data obtained from a teachermade lesson plan and a semi-structured interview. The researcher used content analysis to analyze the lesson plan. Meanwhile, the qualitative data from interview result were preceded through a coding sheet and transcribed modified figure. The findings revealed an integration of SRL cyclical phase and discovery learning in the teacher-made lesson plan. Based on the discussion, the results need to be applied in a considerably large context, in order to see thoroughly dynamic integration between Self-Regulated Learning model, lesson planning and the concept of learner autonomy.
\end{abstract}

Keywords: self-regulated learning, discovery learning, learner autonomy, lesson plan

\section{INTRODUCTION}

Due to the development of learner-centered methods and approaches to teaching English as a foreign language in the current curriculum, the role of teachers and learners have changed. Based on the Indonesian Ministry of Education and Culture (Permendikbud No. 22 , 2016) [6], 2013 Curriculum enhances active learning, multiple sources, scientific approach, competence based approach, integrated learning, applicative learning, and balance of hard skills and soft skills. Based on the overviews, the learner's role in the learning has given an insight to the concept of learner as a critical thinker which means the learner has the authority to control and to develop their own learning. In fact, most of teachers in Indonesia seem to rarely become acquainted with the notion of learner autonomy, especially in lesson planning. Having a well-designed lesson plan actually determines the teaching success (Cunningham, 2009) [3]. However, most of teachers experience several common difficulties in lesson planning such as the way of formulating indicators, selecting materials, determining learning activities, selecting media and developing assessment procedure (Farid, 2014) [9]. Additionally, based on a study conducted in a Learner Autonomy-based teaching training, it was revealed that most teachers actually desired to integrate Learner Autonomy principles in their teachinglearning contexts, but the principles seem to be not feasible for the implementation (Lengkanawati, 2017) [10]. In line with the phenomenon, Farid (2014) [9] also mentions in 
his case study that the teacher made lesson plans tend to be not specific in depicting autonomy into the learning procedure. Thus, the Indonesian teachers tend to be uncertain whether this could be integrated into the lesson plan and teaching practice.

There are some research results which present evidences about SRL and school curriculum in the English as foreign language learning setting. In undergraduate level, Hoops et al. (2016) [8] assert it is essential to teach how to learn, rather than only what to learn, meanwhile all faculty members from all disciplines needs training of curriculum development and effective teaching practices that promote student learning and achievement. However, Borg and Al-Busaidi (2012) [13] report that teachers tend to feel a gap between their desire to implement the concept of autonomy and their practices in particular objectives, assessment and materials. Therefore, teachers play a significant role in motivating student's self-regulation by being a self-regulated teacher (Alsamadani, 2010) [4]. Based on the overview, the concept of SRL in 2013 Curriculum is integrated with Piaget's cognitive theory about cognitive and Vygotsky's social constructivist theory in which learners receive more chances to discover and to interpret ideas by themselves (Asri, 2016) [2]. For teaching procedure, modification is required in the element of learning objective, material development, teaching method and assessment.

Considering the previous elaborations, the present study is intended to extend existing knowledge about Self-Regulated Learning by elaborating the theories in cyclical phase. As past studies dominantly concerned at lesson plan analysis or the theory in teaching practice, this study explores the concept of Self-Regulated Learning in two sections; its integration with discovery learning in the teacher made lesson plan and teacher's perspective about the concept of Self-Regulated Learning (SRL) in lesson planning. The underlying reasons behind this study are there are few researches on Self-Regulated Learning, especially its integration to language learning and lesson planning. Since the current curriculum does not view learners as passive recipients of information, exploring the role of SRL theory in lesson planning contributes an important insight to design a comprehensive lesson plan. It would support the principle of lesson planning based on the content standard (Permendikbud No. 21, 2016) [5], namely to empower students' motivation, creativity, initiative, interest, innovation, inspiration and autonomy.

\section{The Concept of Learner Autonomy and Zimmerman's model of Self- Regulated Learning Cyclical Phase}

The concepts of learner autonomy, independence, and Self-Regulated Learning have been growing throughout the recent years. Learner autonomy is the principle of learners to be encouraged to assume a maximum amount of responsibility for what they learn and how they learn it (Richards \& Schmidt, 2002) [7]. In general, self-regulation refers to the process through which learners systematically direct their thoughts, feelings, and actions toward the attainment of their goals (Rajabi, 2012) [14]. In addition, Lengkanawati (2017) [10] believes that if we teach learners learn how to learn by the use of learning strategies, it is inevitable that we make them become autonomous which in turn will help them have better learning outcomes. As a result, SRL allows learners to learn to control their own behaviour through the social context in which learning occurred and interaction with selfreward.

Zimmerman's model of SRL has been revised several times. In general, it is a cyclical process, where the student plans for a task, monitors their performance, and then reflects on the outcome. Initially, it develops through the integration of cognition, behaviour, emotions and motivation into curriculum and learning. The cyclical phase consists of three major parts, namely forethought phase, performance phase and self-reflection phase as illustrated by the following figure. The first phase, Forethought phase commonly consists of two major process, task analysis and self-efficacy. Just like brainstorming phase, this phase 
fragments learner's background knowledge into smaller pieces and the personal strategies for the performance (Winne, 2001) [11]. The second phase concerns about learner's performance which consists of self-control and self-observation. In this phase, self-control aims at maintaining concentration and interest during performance. The last phase is when learners judge their work and formulate reasons for their results (Zimmerman and Moylan, 2009) [1]. Self-judgment occurs as the process assessing self-performance. As a result, in context of language learning, social cognitive theory views self-regulation as comprising process of self-observation, self-judgment, and self-reaction. Relevant to its purpose, this study explores only the formulation of learning objectives and learning procedure to the theory of Self-Regulated Learning cyclical phase. Thus, extended parts of metacognitive goals such as self-assessment and reflective thinking are embedded in the learning procedure assignments.

\section{RESEARCH METHODS}

This study attempts to explore the integration between a teacher made lesson plan based on 2013 Curriculum and the theory of Self-Regulated Learning cyclical phase through a qualitative method. The design adopted triangulation method in which document analysis was supported by other qualitative methods such as document analysis. The participant in this study was an English teacher who currently teaches at Grade X in a Senior High School level (in this case, vocational school) and her lesson plan. Since the purpose of this study was exploring the integration of SRL cyclical phase to lesson planning, the teacher was expected to be knowledgeable to the concept of learner autonomy and professionally has conducted the concept into language teaching. The main instrument covered the utilization of focused interview to answer the research question about the teacher's perception and a lesson plan checklist to examine the component of the teacher made lesson plan. Focused interview gives an insightful method for gathering information in which the respondent is free to answer the question in her words through open-ended questions (Malik \& Hamied, 2016) [12]. Then, content analysis was deliberately optimized to gather detailed information based on the unit of analysis meanwhile coding process attempted to examine the interview results and to eliminate unnecessary parts which were not related to the research. After lesson plan check, coding and transcription, the data was analysed in four central themes, namely the analysis of the learning objectives, approach/teaching method, learning procedure/activities organization and the teacher's perceptive toward SelfRegulated Learning integration.

\section{RESULTS AND DISCUSSION}

In particular, findings and discussions sections are divided into three subsections following the central themes.

\section{The Learning Objectives}

This lesson plan was made by the teacher for teaching English at tenth grade in a vocational high school. The teachers cover the 90 minutes lesson based on the Core competence and Basic competence written in the national syllabus of English subject for Secondary. The topic of the lesson is about expression of compliment and congratulation which later evolved into eight learning objectives covered in one lesson plan for one meeting:

(2) Learning Objectives

1. Through discussion, learners will be able to mention the social function, language feature and generic structure of the text about giving compliment.

2. Through discussion, learners will be able to define the generic structure of the interactive interpersonal text about giving compliment and giving response autonomously. 
3. Through discussion, learners will be able to mention the social function, language feature and generic structure of the text about congratulation.

4. Through discussing and gathering information, learners will be able to make a congratulation card by using appropriate language feature.

5. Through discussing and gathering information, learners will be able to express compliment and react appropriately.

6. Through discussing and gathering information, learners will be able to arrange the jumbled dialogue into a good conversation about giving compliment and expressing response elaborately.

7. Through discussing and gathering information, learners will be able to compose a proper conversation about giving compliment and congratulation appropriately and elaborately.

8. Through discussing and gathering information, learners will be able to perform a role play about giving compliment and congratulation appropriately and elaborately.

Based on the point (2), action verbs used in the learning objectives vary more than the indicators (to perform, to compose, to arrange, to express, to make, to mention, and to define). The congruence between the indicator and learning objectives are shown in the choice of action verbs and types of objectives written by the teacher. Meanwhile, psychomotor domain appears in the form of making congratulation card, and performing role play. However, affective domain is explicitly integrated through discussion and gathering information session at some point when learners are expected to collaborate together.

\section{The Approach and Teaching Method}

The lesson is designed with scientific approach and the model of learning is discovery learning in which students are engaged to discover ideas and interpret the meaning of the lesson.

(3) Approach: Scientific Approach

Methods: Discovery Learning (Small Group Discussion)

Regarding to the form of 2013 Curriculum lesson planning, the point (3) basically shows complete information of approach, method and technic.

\section{The Learning Procedure Organization}

Since the approach is scientific, the learning of teaching procedure is organized based on the discovery learning. The procedure is presented in three phases, pre-activity, whilstactivity and post-activity.

(4a) Pre-Activity:

- Orientation

- The teacher greets the students, pray together and takes an attendant.

- The teacher asks the students:

- When is your birthday, students?

- What do you say when some is having birthday party?

- What do you say if she's wearing a very beautiful dress on the party?

- Well, students, today we are going to study about how to congratulate and give compliment to other people

- Apperception

- The teacher gives a prominent perceptive about the topic

- Today we will study about giving compliment and congratulation

- Motivation 
- The teacher gives a prompt of giving compliment and congratulation

- Reference

- The teacher states the learning objective and scope of learning.

Regarding to the design, point (4a) already covers pre-activity stages which consists of orientation, apperception, motivation and reference. Concerning the written form, the teacher focuses only on writing the teacher's instruction instead of mentioning learner's activities in each phase. At the same time, the lesson starts with the "when is your birthday?" which depicts SRL forethought phase of setting task goal and building a selfmotivation.

4b) Whilst Activity

- Stimulation

- The teacher gives an example of congratulation card

- The learners observe the cards

- The teacher shows a picture of beautiful lady, a picture of victory, and a picture of graduation day.

- The learners observe the pictures

- Problem statement

- The teacher asks the learners about the pictures

- The learners give their responses

- The learners ask about the way for expressing congratulation in a situation

- The learners ask about the way for expressing compliment.

- The learners give their responses

- Data Collection

- In a small group consist of four people; learners discuss the structure of the text about expressing compliment, giving response and extended expression.

- In the group, learners gather information about interactive text, both in written and spoken form, about expressing compliment, giving response and extended expression.

- Verification

- The teacher asks the learners to identify the social function, generic structure and language feature of the text.

4c) Post-Activity

- The learners arrange a jumbled conversation into a good dialogue.

- With the teacher, the learners derive a conclusion from the lesson about social function, generic structure and language feature of the text.

- The teacher gives instruction about the upcoming homework about making a congratulation card.

Regarding the suitability of the learning procedures with the learning objectives, this whilst activities seem to affect more cognitive domain. In fact, the lesson plan seems already provide a space for doing task strategies elaboration through the stimulation part. In contrast, in the point (7) and (8) of the learning objectives, the students are expected to be able to compose a congratulation card and to perform a dialogue. Meanwhile, in verification session, learners are expected to only identify social function, generic structure and language feature and to arrange jumbled dialogue. According to point $4 \mathrm{c}$, the instructions tend to be not sufficient enough to complete all learning objectives written in the first part. In line with Alsamadani (2010) [4] who states that self-regulation would happen only if the teacher could model it by being a self-regulated teacher first. In this case, she gives reinforcement and reward to the learners in order to help them become selfregulated. For this reason, external motivations such as reward and types of reinforcement need to be mentioned in the lesson plan in order to comprehensively inform every teacher who could use the lesson plan. 


\section{CONCLUSION}

Based on the overview, the teacher made lesson plan already contain all component of lesson plan based on the process standard of 2013 Curriculum. However, there are several sessions of the learning procedure in the lesson plan that does not constitute a complete feature of the cyclical phase. As a result, a comprehensive reinforcement and reward need to be attached in the lesson plan in order to give a better insight of metacognitive goals of the lesson plan.

\section{ACKNOWLEDGEMENTS}

I would like to express my gratitude to Prof. Dr. Nenden Sri Lengkanawati, M.Pd. for her constructive suggestions during the course and my peers for their supportive advice and my very great appreciation to LPDP (Indonesia Endowment Fund for Education) Scholarship for supporting my postgraduate study.

\section{REFERENCE}

1. B. J. Zimmerman, A. R. Moylan, Handbook of Metacognition in Education, 299-315 (2009)

2. D. N. Asri, Counsellia: Jurnal Bimbingan dan Konseling, 4 (2016).

3. G. Cunningham, The new teacher's companion: practical wisdom for succeeding in the classroom, (2009)

4. H. A. Alsamadani, Eur. J So. Sci., 16, 51 (2010)

5. Indonesian Ministry of Education and Culture, Permendikbud No. 21 (2016)

6. Indonesian Ministry of Education and Culture, Permendikbud No. 22 (2016)

7. J. C. Richards, R. Schmidt, Longman dictionary of language teaching and applied linguistics (2002)

8. L. D. Hoops, S. L. Yu, Q. Wang, V. L. Hollyer, IJTLHE, 28, 75-93. (2016)

9. M. Farid, Teachers'difficulties in lesson planning (Doctoral dissertation, Universitas Pendidikan Indonesia) (2014)

10. N. S. Lengkanawati, IJAL, 6, 222-231 (2017)

11. P. H. Winne, Self-regulated learning and academic achievement, 153-190 (2001)

12. R. S. Malik, F. A. Hamied, Research methods, (2016)

13. S. Borg, S. Al-Busaidi, ELT J, 12, 1 (2012)

14. S. Rajabi, Procedia So. Be. Sci., 47, 344-350 (2012) 